\title{
Intraoperative rupture of blood blister-like aneurysm: a case report and review of literature
}

\author{
Roodrajeetsing Gopaul, Wen Shao Xiao*, Jun Yan and Dang Zong Wei
}

\begin{abstract}
Blood blister-like aneurysms (BBLAs) are aneurysms from the non-branching sites of the internal carotid artery (ICA). Though rare lesions, they pose a high risk of intraoperative aneurysmal rupture. Definite treatment of these types of aneurysms has been debatable, but surgical approach is the ultimate rescue treatment. Microsuture of the intraoperative ruptured BBLA has been reported scarcely in literature, but no review of these cases has ever been reported. We here present our experience of a case of BBLA intraoperative rupture requiring microsuture of the ICA and conduct meticulous review of all similar cases.
\end{abstract}

Keywords: Blood blister-like aneurysm (BBLA), Angiogram-negative subarachnoid hemorrhage (SAH), Intraoperative rupture

\section{Introduction}

First described by Sundt and Murphey [1], blood blisterlike aneurysms (BBLAs) or frog-eye aneurysms are frequently seen at the non-branching sites of the supraclinoid internal carotid artery. Higher incidences of BBLAs have been reported among women, on the right side, in younger patients with subarachnoid hemorrhage (SAH), associated hypertension and arteriosclerosis, or dissection of the internal carotid artery (ICA) [2, 3]. Their bulging appearance with a broad base ostium indicates a "sick" carotid wall segment differing from the overall group of saccular aneurysms [4]. BBLAs of the ICA account for about $0.3-1 \%$ of intracranial aneurysms or $0.9-6.5 \%$ of ICA aneurysms [5].

BBLAs are thin and fragile hemispherical bulges and can progress into a saccular shape. They are at high risk of recurrent hemorrhage no matter their shape or the treatment modality chosen [5]. These lesions account for $0.5-2.0 \%$ of ruptured intracranial aneurysms and prelude unusually high morbidity and mortality rates compared with typical ruptured saccular aneurysms of the ICA [6]. A high degree of suspicion for this lesion is recommended in SAH of unknown origin, particularly when the bleeding pattern is more typical for an ICA

\footnotetext{
* Correspondence: pawangopaul@yahoo.com

Department of Neurosurgery, First Affiliated Hospital, Guangxi Medical University, 6 Shuang Yong Road, 530021 Nanning, Guangxi Zhuang Autonomous, People's Republic of China
}

source [7]. However, similar lesions can be found at lower frequencies in other areas of the basal cerebral circulation (e.g., in the basilar artery) $[8,9]$. Because these lesions are often not true aneurysms but rather pseudoaneurysms with a high incidence of thin and fragile walls and lack a definable neck, they are extremely difficult to treat surgically. This difficulty is reflected by a high incidence of intraoperative rupture and postoperative hemorrhage, resulting in significant disability and mortality from surgical repair [10].

Although endovascular techniques have revolutionized the treatment of aneurysms in general, these blister-like aneurysms present a challenge because of their small size, wide necks, and fragile nature. Treating these aneurysms surgically is usually not a problem, but surgeons are often faced with a hole in the carotid when the aneurysm disintegrates during dissection [11]. BBLAs are uncommon and their management is subsequently based on what little has been published. The angiographic diagnosis of BBLAs may be difficult because they often represent tiny lesions that can be overlooked, mistaken for artifacts or focal atheromatous irregularity, or missed completely due to overlap of vessel curvature [10]. Repeat angiography often documents luminal changes or growth of these lesions.

In many patients with this particular type of aneurysm, soon after subarachnoid hemorrhage, the initial angiogram shows only a small bulge, which may progress to a saccular appearance within a few weeks [12]. Exact pathogenesis 
of BBLA is unknown, but several autopsy studies suggest that BBLA is not a true saccular aneurysm but a specific type of pseudoaneurysm and that a small ulceration penetrating the internal elastic lamina and the resulting wall defect is crucial in BBLA development. Others suggest that BBLA is specifically a type 4 dissection with focal defect of the internal elastic lamina mimicking a penetrating ulceration without a coexisting intramural hematoma, a condition similar to BBLA [13].

\section{Review}

\section{Case report}

A 68-year-old male suffering from acute headache for 4 days presented to the emergency department of Guangxi Medical University. The patient was alert on physical examination, muscle tension grade 5 in all limbs, and both pupils were same size of $3 \mathrm{~mm}$ and sensitive to pupillary light reflex. The neck was slightly stiff on examination, and Kernig's sign and Brudzinski's sign were slightly positive. Emergent CT scan was carried out showing SAH (Fig. 1a). The patient was then admitted to the neurosurgery department where computed tomography angiography (CTA) was carried out revealing similar results to CT scan in addition to right $\mathrm{C} 7$ (communicating artery) segment right internal carotid artery aneurysm of size $2.3 \mathrm{~mm} \times 2.8 \mathrm{~mm}$ (Fig. 1b, c). No other aneurysms or vascular malformations could be noted to relate the cause of SAH. SAH Hunt and Huss Grade II, without focal neurological deficit, were noticed. Severity of the disease, complications, risks, and therapeutic options were clearly discussed with family members and the patient. Cons of endovascular treatment outweighed pros due to its broad base and small and fusiform morphology. A final decision of open surgery for aneurysm clipping was made.

The patient underwent general anesthesia, and right pterion approach was chosen. Direct exposure of a $2 \mathrm{~mm} \times$ $1.5 \mathrm{~mm}$ bulge at the bifurcation of internal carotid artery (ICA) and posterior communicating artery (PCA) and signs of arteriosclerosis (yellowish plaques) could be seen (Fig. 2a). Blister-like appearance, thin wall, clear hemodynamics could be seen at the lesion wall. A 10-ml hematoma was present at the proximity of bifurcation of these two arteries (Fig. 2b).

A temporary clip was inserted on the victim's artery and the vision cleared for proper exposure. Debridement of the hematoma was carried out when suddenly the blood blister-like aneurysm ruptured and a "hole" could be seen (Fig. 2c, d). There was spontaneous bleeding and

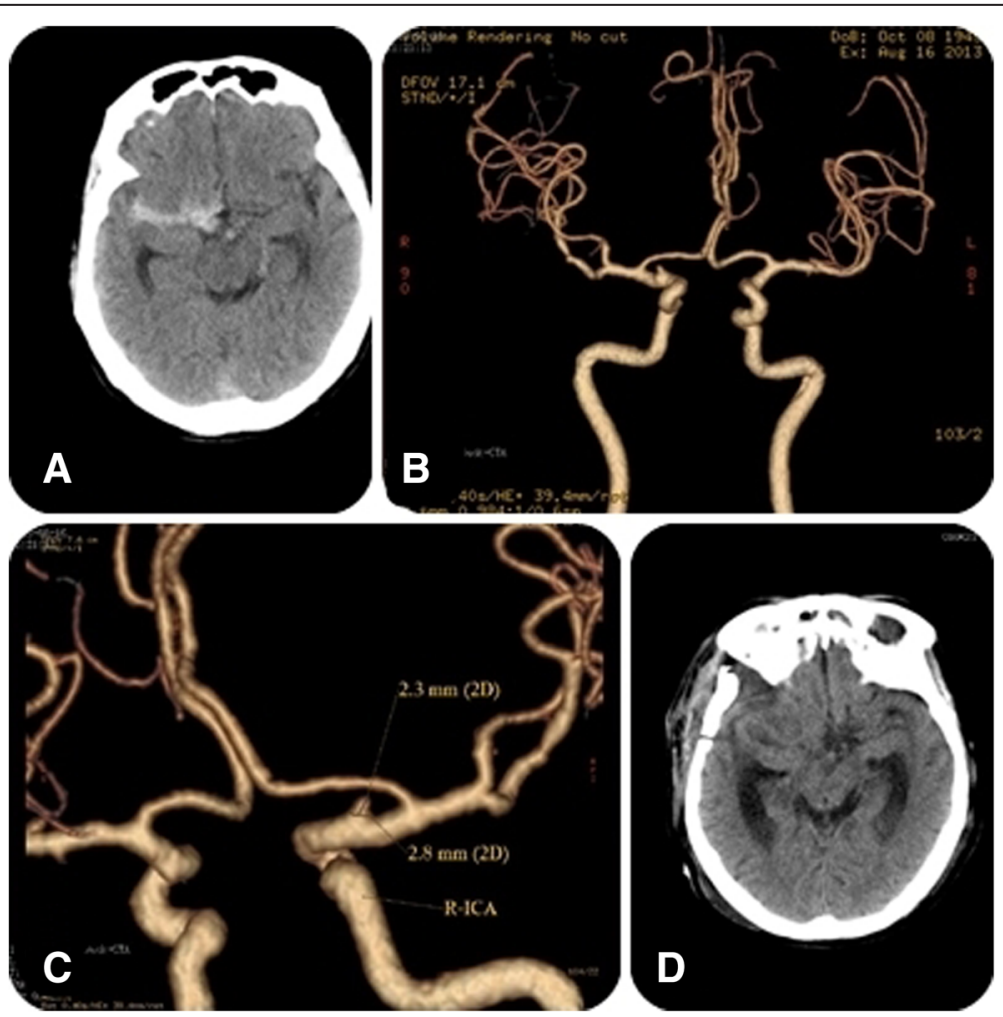

Fig. 1 Radiological findings in patient. a Computed tomography (CT) taken at the time of admission to the hospital showing SAH. b Computed tomography angiography (CTA) taken 1 day after hospital admission showing right C7 (communicating artery) segment right internal carotid artery aneurysm. c Better illustration and measurements of aneurysm of size $2.3 \times 2.8 \mathrm{~mm}$. $\mathbf{d}$ CT presentation 35 days after surgery showing no $\mathrm{SAH}$ and no postoperative cerebral infarction 


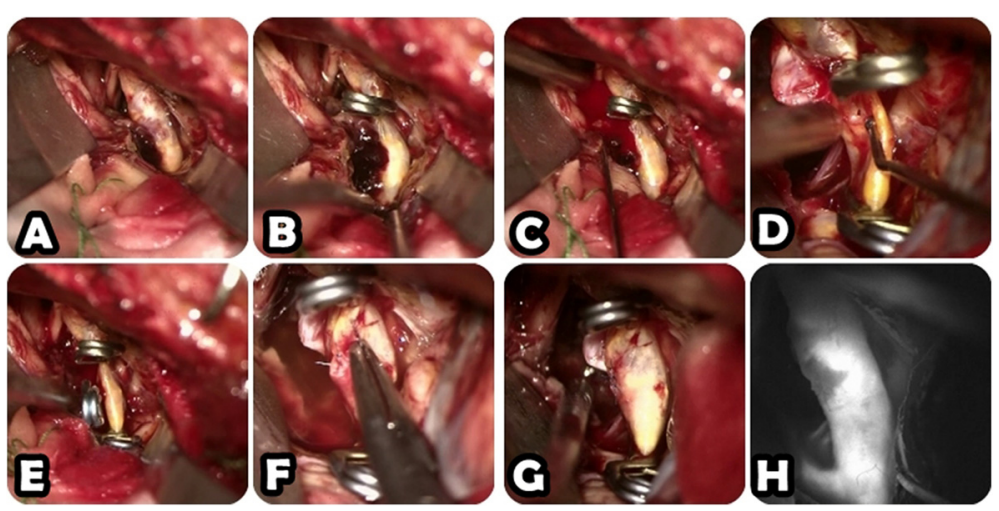

Fig. 2 a Gross BBLA appearance showing blood clot around the parent artery. b Magnified view of aneurysm and hematoma with temporary clip. c Intraoperative rupture of aneurysm while dissecting hematoma. $\mathbf{d}$ "Hole" in ICA seen, two temporary clips applied on both sides of ICA BBLA to prevent heavy bleeding. e Attempt to apply permanent clip in different positions but with no proper grasp. $\mathbf{f}$ Microsuturing of ICA needing three sutures of 8/0 Prolene. $\mathbf{g}$ View of ICA after three 8/0 Prolene stitches. $\mathbf{h}$ Intraoperative fluorescein angiography showing no ICA obstruction

another temporary clip was inserted to prevent blood loss. The ruptured vessel wall was exposed, and a permanent clip was attempted several times in different angles but all in vain as there was no proper grip of the clip (Fig. 2e). Vessel reconstruction was attempted and vessel wall of the tear was approximated by three $8 / 0$ Prolene sutures and total temporary clipping time of $22 \mathrm{~min}$. The temporary clips were carefully released one at a time, and blood flow was monitored (Fig. 2f, g). The artery was properly dilated with no blood leakage noticed. Surgical vision was rinsed with NS, and intraoperative fluorescein angiography showed no vessel obstruction (Fig. 2h). The patient was regularly followed with cranial CTs, and no cerebral infarction or other complications were detected (Fig. 3). The patient did fairly well after surgery, but because the patient lives $440 \mathrm{~km}$ from our institute,

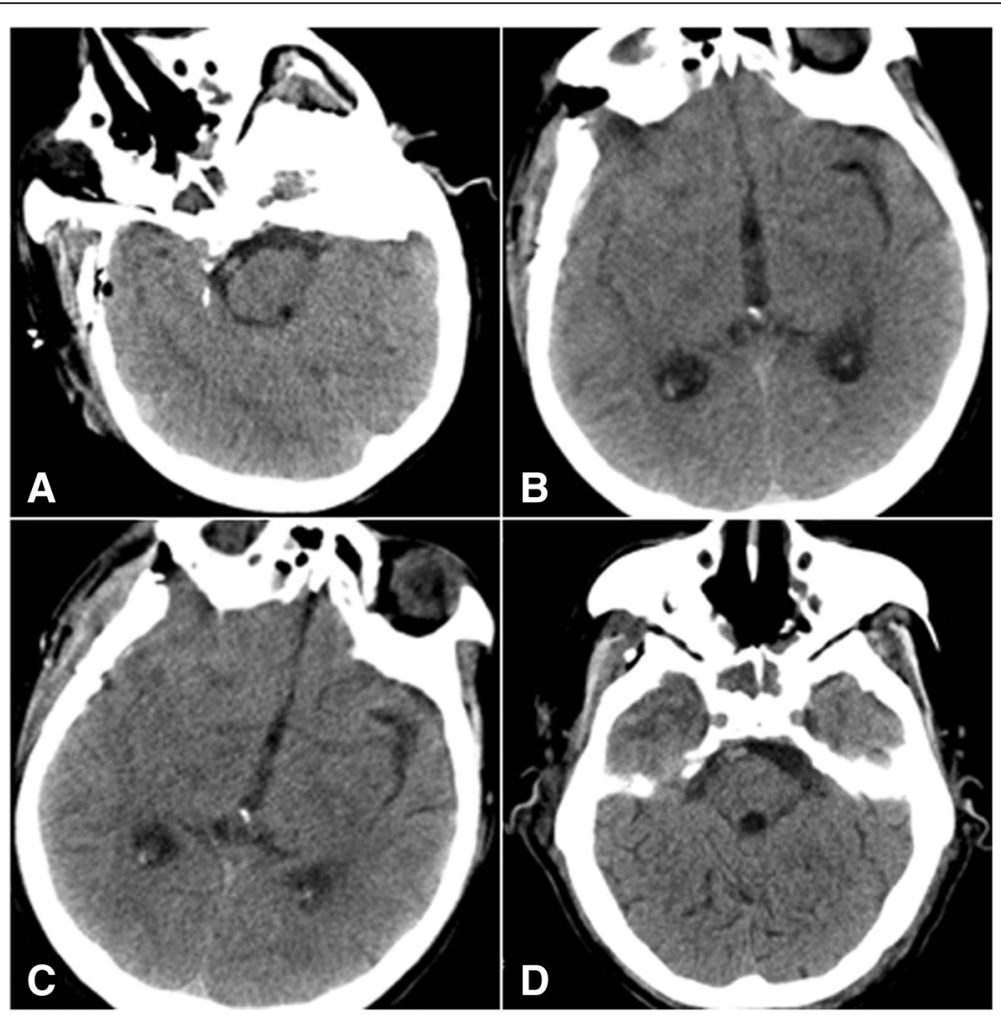

Fig. 3 a Intraoperative cranial $\subset$ showing proper evacuation of hematoma. b Cranial $\subset$ on day 6 post surgery showing no cerebral infarction. c Cranial $\subset$ on day 10 post surgery showing no significant hydrocephalus. $\mathbf{d}$ Cranial $\subset$ on day 50 post surgery showing uneventful postoperative recovery 
we contacted the patient 9 months after surgery and evaluation using modified Rankin scale score was 3 at 8 months after surgery (moderate disability).

\section{Discussion}

Sundth and Murphey were the first to describe the lesions at non-branching sites on internal carotid artery (ICA). Preoperative diagnosis of BBLA is very challenging, and angiographic findings do not always correlate with the intraoperative features. BBLA might be one of the causes of angiogram-negative subarachnoid hemorrhage (SAH), particularly when the distribution of blood on computed tomography $(\mathrm{CT})$ is non-perimesencephalic [14]. So, in many cases of SAH, the first angiographic findings of CTA or even digital subtraction angiography (DSA) are negative or suspicious and repeated exams must be done [15]. Short-term angiography follow-up (10 days) may show a dramatic change in the conformation of these lesions with reasons attributed to the profound weakness of the aneurysmal wall [16]. Recently, the use of CTA as a first-line diagnostic tool has been advocated on the basis of comparable sensitivity and specificity to DSA even for small aneurysms [17]. Blood blister-like aneurysms are most correctly diagnosed when proper visualization of the aneurysm is obtained intraoperatively.
Treatment options for BBLA include conservative, endovascular treatment and surgical treatment. Although several strategies in each subgroup have been attempted by centers across the globe, no consensus has been reached for the safest treatment modality because clinical outcomes have generally remained poor $[5,18]$. Table 1 shows a review of previous cases in literature reporting intraoperative microsuture cases; note must be taken that many of these cases employed microsuture as a rescue treatment after intraoperative rupture of aneurysm. The ideal treatment outcome is blister-like aneurysm repair with parent artery preservation. However, due to patient preference, open surgery was opted in our present case and intraoperative rupture of aneurysm occurred.

Kojra et al. [19] concluded that stent-assisted coil embolization is not a treatment of choice for BBLA but only an option. Parker at al. [20] concluded that endovascular coiling of BBLA cannot be recommended as a treatment strategy due to high rates of procedural rupture (75\%), aneurysmal regrowth, and rebleeding. Maling et al. [21] further discouraged endovascular treatment as 11 out of 14 of their patients were judged unsuitable in BBLA treatment. There are no randomized controlled trials and meta-analyses to compare the endovascular and surgical treatments of BBLA, therefore making it difficult to encourage any particular treatment plan. Moreover, to date,

Table 1 Review of reported intraoperative aneurysm microsuture cases

\begin{tabular}{|c|c|c|c|c|c|c|c|}
\hline $\begin{array}{l}\text { Reference } \\
\text { number }\end{array}$ & Age/sex & $\begin{array}{l}\text { SAH } \\
\text { grade }\end{array}$ & Location & Surgical strategy & $\begin{array}{l}\text { Stenosis } \\
\text { of artery }\end{array}$ & $\begin{array}{l}\text { Patency } \\
\text { confirmation }\end{array}$ & Outcomes \\
\hline Vashu et al. [24] & $14 / F$ & $\begin{array}{l}\text { WFNS } \\
\text { Grade II }\end{array}$ & $\begin{array}{l}\text { Right supraclinoid } \\
\text { ICA aneurysm }\end{array}$ & $\begin{array}{l}\text { 8/0 Prolene } 4 \text { stitches-20-min } \\
\text { clipping + barbiturate }\end{array}$ & No & CTA & $\begin{array}{l}\text { No neurological deficit-no } \\
\text { recurrence at } 11 \text { months } \\
\text { follow-up }\end{array}$ \\
\hline Vashu et al. [24] & $48 / F$ & $\begin{array}{l}\text { WFNS } \\
\text { Grade I }\end{array}$ & $\begin{array}{l}\text { Right supraclinoid } \\
\text { ICA aneurysm }\end{array}$ & $\begin{array}{l}\text { 7/0 Prolene } 4 \text { stitches-23-min } \\
\text { clipping + another } 28 \text {-min clipping } \\
\text { + barbiturate }\end{array}$ & No & DSA & $\begin{array}{l}\text { GOS- } 5 \text { at } 5 \text { months follow-up, } \\
\text { left side limb weakness } 4 / 5\end{array}$ \\
\hline Yanaka et al. [25] & $46 / F$ & $\mathrm{H} \& \mathrm{H} I I I$ & $\begin{array}{l}\text { Right supraclinoid } \\
\text { ICA aneurysm }\end{array}$ & $\begin{array}{l}8 / 0 \text { nylon } 2 \text { stitches-Surgicel + } \\
\text { fibrin glue }+ \text { encircling clip }\end{array}$ & Spasm & DSA & $\begin{array}{l}\text { Returned to normal activities } \\
\text { at } 3 \text { months follow-up }\end{array}$ \\
\hline Lee et al. [7] & $46 / F$ & $\mathrm{H} \& \mathrm{H} \|$ & $\begin{array}{l}\text { Left dorsolateral } \\
\text { ICA }\end{array}$ & $\begin{array}{l}\text { Suture-temporary clip time } \\
36 \text { min }\end{array}$ & NM & NM & Global infarction—death \\
\hline Otani et al. [17] & $40 / F$ & $H \& H V$ & Right ICA & Clip on wrapping with suture & Spasm & NM & Moderate disability \\
\hline Park [26] & $58 / F$ & & $\begin{array}{l}\text { Right superior to } \\
\text { medial wall ICA } \\
\text { aneurysm }\end{array}$ & 8/0 polypropylene & No & DSA & mRs 3 at 3 months follow-up \\
\hline Joo et al. [23] & $30 / \mathrm{M}$ & H\&H III & Left ICA & $\begin{array}{l}\text { Suture tear with } 8 / 0 \text { nylon } \\
+ \text { wrapping + clipping-20 min }\end{array}$ & $\begin{array}{l}\text { ICA } \\
\text { occluded }\end{array}$ & DSA & Discrete hemiparesis (4/5) \\
\hline Joo et al. [23] & $33 / \mathrm{M}$ & FISHER III & $\begin{array}{l}\text { Right supraclinoid } \\
\text { ICA aneurysm }\end{array}$ & $\begin{array}{l}\text { Suture with } 8 / 0 \text { nylon }+ \\
\text { wrapping + clipping }\end{array}$ & NO & DSA & Good \\
\hline Our case & $68 / M$ & $\mathrm{H} \& \mathrm{H} \|$ & $\begin{array}{l}\text { Right supraclinoid } \\
\text { ICA aneurysm }\end{array}$ & $\begin{array}{l}\text { 8/0 Prolene } 3 \text { sutures-22-min } \\
\text { clipping }\end{array}$ & NM & NM & mRS 3 at 8 months follow-up \\
\hline
\end{tabular}

As we can see from Table 1, male to female ratio is 2:1, age distribution of 14-68 years old (mean age of 43 years old). Seven out of these 9 cases (77.8 \%) were from the right side, and right supraclinoid ICA aneurysms seem to be more common. 8/0 Prolene sutures were preferred for suturing, and average time of temporary clipping of ICA was $26 \mathrm{~min}$. All the BBLA in this review was intraoperatively ruptured and then sutured. No reports of rebleeding or recurrence were noted, and the postoperative outcomes were good except in one case where the patient died

$M$ male, $F$ female, WFNS World Federation of Neurosurgeons Subarachnoid Hemorrhage (SAH) Grading System, H\&H Hunt and Hess SAH Scale, FISHER Fisher SAH Grade, GOS Glasgow Outcome Scale, mRs modified Rankin scale, NM not mentioned, CTA computed tomography angiography, DSA digital subtraction angiography 
all the present cases in literature used microsuturing as the rescue treatment of BBLA.

Various surgical strategies have been developed to fight against BBLA, including parallel clip placement along the ICA wall producing mild stenosis, clipping on wrapping methods, trapping with or without extracranial-intracranial bypass surgery, and suturing methods. Most surgical case series reported that BBLA had a worse outcome than usual ruptured saccular aneurysms. The BBLA wall is fragile; direct clipping of the aneurysm neck is dangerous and likely to cause premature rupture during surgical manipulation [13].

From our review of literature, as illustrated in Table 1, we noticed that suturing was used as a rescue plan when BBLAs ruptured intraoperatively. Postoperative angiography showed no vessel stenosis in four patients but two patients had vessel spasm. DSA was the preferred follow-up tool to re-evaluate patient after BBLA rupture and suture. Gonzalez [7] carried a systemic review of surgically treated blood blister-like aneurysms, and out of 165 patients with clipping, 39 (23\%) needed rescue treatment. Out of these 39 patients, 10 (25.6\%) patients received arterial microsuture. This shows that arterial microsuture is a fundamental technique for neurovascular surgeons.

Suturing has been infamous because of the lack of experience, fragile muscle wall, bleeding, prolonged ischemic time, and uncertain outcomes. Suturing methods and surgical handlings can be difficult because of the limited space and time. Yanaka et al. [22] agreed that aneurysmal rupture requiring arterial suture does not occur often, but a proper strategy to address such problems can make a difference in bringing a good neurological outcome out of an intraoperative catastrophe. They suggest that deep field suturing required long microsuture forceps and long microneedle holder, and these instruments must be prepared and available in the operating room.

However, there are certain limitations to this technique, such as excessive vessel laceration, making suturing cause too much stenosis and extensive circumferential carotid disease. Joo et al. attempted suturing in a patient after several failed attempts of failed clipping, but the follow-up DSA demonstrated internal carotid artery occlusion [23]. In such cases, parent vessel occlusion and bypass can be considered.

\section{Conclusions}

In conclusion, BBLAs are rare but very unpredictable lesions. Proper teamwork between the neurosurgeon and interventional neuroradiologist can improve efficacy of treatment. Angiogram-negative subarachnoid hemorrhage patients must be suspected of BBLA and 3D CTA (in preference to 2D DSA) or 3D DSA (in preference to 3D CTA) can be repeated about 10 days after initial SAH. Intraoperative rupture of BBLA is very common, and we here report that arterial microsuture can be a good reliable rescue treatment. Also, in many medical centers as ours, there is no wide variety of stents and encircling clips are not available; suturing is the very practical in these situations as a lifesaving procedure. We therefore strongly suggest that any medical institution providing surgical treatment option for aneurysmal treatment should have team members well trained in arterial microsuturing techniques and should have readily available long microsuture forceps and long microsuture needle holders.

\section{Consent}

Written informed consent was obtained from the patient for the publication of this report and any accompanying images

\section{Competing interests}

The authors declare they have no competing interests.

\section{Authors' contributions}

Conception and design: RG, DZW. Acquisition of data: RG, DZW. Analysis and interpretation of data: All authors. Drafting the article: all authors. Critically revising the article: all authors. Reviewed submitted version of manuscript: all authors. Approved the final version of the manuscript on behalf of all authors: RG. Statistical analysis: RG. Administrative/technical/material support: WSX, JY, RG. Study supervision: WSX, JY, RG. All authors read and approved the final manuscript.

\section{Acknowledgements}

We are grateful to Ms. Purvarshi Gowreesunkur for her help in language editing and Ms. Lu Gui Hua for her support during this research.

Received: 28 April 2015 Accepted: 7 September 2015

\section{Received: 28 April 2015 Accepted: 7 Septemt}

\section{References}

1. Sundt Jr TM, Murphey F. Clip-grafts for aneurysm and small vessel surgery. 3. Clinical experience in intracranial internal carotid artery aneurysms. J Neurosurg. 1969:31:59-71.

2. Akira O, Michiyasu S, Kuniaki O. Aneurysms at nonbranching sites in the supraclinoid portion of the internal carotid artery: internal carotid artery trunk aneurysms. J Neurosurg. 2000;47(3):578.

3. Ogawa A, Suzuki M, Ogasawara K. Aneurysms at nonbranching sites in the surpaclinoid portion of the internal carotid artery: internal carotid artery trunk aneurysms. Neurosurgery. 2000;47:578-83. discussion 583-86.

4. Regelsberger J, Matschke J, Grzyska U, Ries T, Fiehler J, Köppen J, et al. Blister-like aneurysms - a diagnostic and therapeutic challenge. Neurosurg Rev. 2011;34:409-16.

5. Nancy ML, Mathieu L, Bojanowski MW. Surgical management of blood blister-like aneurysms of the internal carotid artery. World Neurosurg. 2010;74(4/5):483-93.

6. Fang Y-B, Li Q, Yang P-F, Huang Q-H, Zhao W-Y, Xu Y, et al. Treatment of blood blister-like aneurysms of the internal carotid artery with stent-assisted coil embolization. Clin Neurol Neurosurg. 2013;115:920-5.

7. Ana Marcos G, Ana Paula N, Hasan Y, Philippe B, Ivan R, Karl S, et al. Blood blister-like aneurysms: single center experience and systematic literature review. Eur J Radiol. 2014;83:197-205.

8. Fiorella D, Albuquerque FC, Deshmukh VR, Woo HH, Rasmussen PA, Masaryk $T$, et al. Endovascular reconstruction with the Neuroform stent as monotherapy for the treatment of uncoilable intradural pseudoaneurysms. Neurosurgery. 2006;59:291-300. discussion 291-300.

9. Parka SI, Kimb BM, Kimb DI, Shinc YS, Suhd SH, Chunge EC, et al. Clinical and angiographic follow-up of stent-only therapy for acute intracranial vertebrobasilar dissecting aneurysms. AJNR Am J Neuroradiol. 2009;30:1351-6 
10. Meckel S, Singh TP, Undre'n P, Ramgren B. Endovascular treatment using predominantly stent-assisted coil embolization and antiplatelet and anticoagulation management of ruptured blood blister-like aneurysms. AJNR Am J Neuroradiol. 2011;32:764-71.

11. Le feuvre DEJ, Taylor AG. The management of very small/blister internal carotid artery aneurysms. Interv Neuroradiol. 2011;17:431-4.

12. Abe M, Tabuchi K, Yokoyama H, Uchino M. Blood blister aneurysm of the internal carotid artery. J Neurosurg. 1998;89:419-24.

13. Lim YC, Kim BM, Suh SH, Jeon P, Kim SH, Ihn YK, et al. Reconstructive treatment of ruptured blood blister-like aneurysms with stent and coil. Neurosurgery. 2013;73(3):480.

14. Morris TC, Brophy BP. Blister-like aneurysm of the anterior communicating artery. Case Reports/J Clin Neurosci. 2009;16:1098-100.

15. Otani N, Takasato Y, Masaoka H, Hayakawa T, Yoshino Y, Yatsushige H, et al. Clinical and radiological findings and surgical management of ruptured aneurysms at the non-branching sites of the internal carotid artery. J Clin Neurosci. 2009;16:1018-23.

16. Alim AP, Spetzler RF. Blister-like aneurysms: an enigma of cerebrovascular surgery. World Neurosurg. 2010. doi:10.1016/j.wneu.2010.10.006.

17. Norberto A, Mario Z. Blister-like aneurysms of the anterior communicating artery: a retrospective review of diagnosis and treatment in five patients. Neurosurgery. 2008;62(4):807.

18. Tack GC, Sung NH, Taek KN, Seung WP. Salvage surgical treatment for failed endovascular procedure of a blood blister-like aneurysm. J Cerebrovasc Endovasc Neurosurg. 2012;14(2):98-103.

19. Korja M, Rautio R, Valtonen S, Haapanen A. Primary treatment of ruptured blood blister-like aneurysms with stent-assisted coil embolization: report of two cases. Acta Radiol. 2008;49:180-3.

20. Park JH, Park IS, Han DH, Kim SH, Oh CW, Jeong-Eun K, et al. Endovascular treatment of blood blister like aneurysms of the internal carotid artery. J Neurosurg. 2007;106:812-9.

21. Meling TR, Sorteberg A, Bakke SJ, Slettebø H, Hernesniemi J, Sorteberg W. Blood blister-like aneurysms of the internal carotid artery trunk causing subarachnoid hemorrhage: treatment and outcome. J Neurosurg. 2008;108:662-71.

22. Lee J-W, Choi H-G, Jung J-Y. Surgical strategies for ruptured blister-like aneurysms arising from the internal carotid artery: a clinical analysis of 18 consecutive patients. Acta Neurochir. 2009;151:125-30.

23. Joo S-P, Kim T-S, Moon K-S. Arterial suturing followed by clip reinforcement with circumferential wrapping for blister-like aneurysms of the internal carotid artery. Surg Neurol. 2006;66:424-9.

24. Vashu R, Tan S, Wong ASH. Microsuture repair of intra-operative ruptures of cerebral aneurysms of the internal carotid artery. J Clin Neurosci. 2009;16:960-2.

25. Yanaka K, Meguro K, Nose T. Repair of a tear at the base of a blister like aneurysm with suturing and an encircling clip: technical note. Neurosurgery. 2002;50(1):218

26. Park J. Maintenance of cerebral blood flow during microsuture repair of the superior wall of the intracranial internal carotid artery. World Neurosurgery. 2013;80(3/4):436. e1-436.e5.

\section{Submit your next manuscript to BioMed Central and take full advantage of:}

- Convenient online submission

- Thorough peer review

- No space constraints or color figure charges

- Immediate publication on acceptance

- Inclusion in PubMed, CAS, Scopus and Google Scholar

- Research which is freely available for redistribution

Submit your manuscript at www.biomedcentral.com/submit 